\title{
Operant performance as a function of novelty of reward'
}

GLEN D. JENSEN, State University of New York, College at Fredonia, N.Y. 14063, and LINNUS S. PECAUT, De Paul University, Chicago, Ill. 60604

Wide differences in amount of exposure to and ingestion of Noyes food pellets did not significantly affect rate of responding to earn Noyes pellets under either CRF or fixed-ratio scheduling. Body weight data suggests that Noyes pellets are equally nourishing relative to Purina food for rats.

In many experiments certain groups of rats receive larger numbers of Noyes food pellets than other groups. Thus, relative novelty of rewards is often confounded with the independent variable. The present study attempts to determine how serious this confounding is likely to be. It is also possible that Noyes pellets are not equally nourishing, on a per gram basis, relative to the type of food being used as the bulk of a rat's diet. This study provides ancillary evidence regarding the relative nutritive value of Noyes pellets and one widely used type of maintenance diet, namely, Purina checkers.

Subjects

\section{METHOD}

Sixty naive male Sprague-Dawley rats all weighing about $200 \mathrm{~g}$, served as Ss.

Apparatus

Four Skinner boxes comparable to the one described by Jensen (1961) were used. An Ohaus Autogram 1000 balance was used to weigh rats, Noyes, pellets, and finely-ground Purina checkers.

Procedure

After the 60 rats had already been assigned to individual Hoeltge cages, they were assigned by table of random numbers to four groups, each containing 15 Ss. For four days after the randomized assignment all Ss continued on a diet of $10 \mathrm{~g}$ of finely-ground Purina checkers per day. (This diet had been in effect for 10 to 40 days for particular rats.) These four days will henceforth be called "Days 1-4." Weight data suggests that the typical rat was neither gaining nor losing weight during Days 1-4.

Ss in Groups P-120A and P-10E continued to receive $10 \mathrm{~g}$ of ground Purina per day during Days 5-11. Ss in Groups N-120A and $\mathrm{N}-10 \mathrm{E}$ were fed $10 \mathrm{~g}$ of $45 \mathrm{mg}$ Noyes pellets per day during Days 5-11.

On Day 12 each $S$ received a dispenser training session in the Skinner box. One $45 \mathrm{mg}$ pellet was automatically delivered every $30 \mathrm{sec}$ until 50 pellets had been delivered and eaten.

On Day 13 each $S$ was allowed to make 20 bar presses, each rewarded with one $45 \mathrm{mg}$ pellet. This session served to build enough response strength for introduction of a fixed-ratio schedule on Day 14.

On Day 14 Ss in Groups P-120A and N-120A were allowed to make 120 rewarded presses. Ss in Groups P-10E and N-10E were
Table 1

Mean Number of Bar-Pressing Responses During $30 \mathrm{~min}$ of Extinction

\begin{tabular}{lccc}
\hline $\begin{array}{l}\text { Type of Food Composing the } \\
\text { Bulk of the Daily Ration }\end{array}$ & \multicolumn{2}{c}{$\begin{array}{c}\text { Type of Schedule } \\
\text { During Day 14 }\end{array}$} & $\begin{array}{l}\text { Row } \\
\text { During Days 5-15 }\end{array}$ \\
\cline { 2 - 3 } & $120 \mathrm{~A}$ & $10 \mathrm{E}-1 \mathrm{~A}$ & \\
\hline Noyes Pellets & 161.1 & 236.0 & 198.1 \\
Ground Purina Chow & 130.5 & 212.3 & 171.3 \\
Column Means & 145.7 & 223.8 & \\
\hline
\end{tabular}

also allowed to receive 120 pellets, but only every 11 th press was rewarded. The design was a 2 by 2 factorial with either ground Purina (P) or Noyes pellets $(\mathrm{N})$ being used to make up the differences between the weight of pellets earned in the Skinner box and the $10 \mathrm{~g}$ daily ration, and with either CRF scheduling (120A) or else 10E-1A scheduling on Day 14. In the expression $10 E-1 A$, "E" stands for extinction and " $A$ " stands for acquisition. The 10E-1A schedule was chosen because it represents a fairly small percentage of reinforcement and yet most rats can negotiate it with no great difficulty. By the choice of these schedules, the present results can reasonably be generalized over the range of 9 to $100 \%$ reinforcement.

On Day 15 each $S$ was given a $30-$ min extinction session.

During Days 12-15 Ss in Groups N-120A and N-10E were always fed the remainder of their daily $10 \mathrm{~g}$ ration in the form of Noyes pellets $1 / 2 \mathrm{~h}$ after the end of the experimental session, while Ss in Groups P-120A and P-10E received $10 \mathrm{~g}$ (minus the weight of all pellets received) in the form of ground Purina. Water was available to all Ss at all times.

\section{RESULTS}

Table 1 summarizes the findings with respect to number of bar presses made during the final extinction session (Day 15). Type of schedule was significant $(F=25.4, \mathrm{df}=1 / 56, \mathrm{p}<.01)$, as could be expected from many prior experiments on partial reinforcement. The most important finding is that the exposure to and ingestion of 2,200 additional Noyes pellets by each rat in the top row relative to each rat in the bottom row did not significantly alter rate of responding $(F=2.99, \mathrm{df}=1 / 56, \mathrm{p}>.05)$. There was a very negligible interaction between type of food and type of schedule $(\mathrm{F}=.06, \mathrm{df}=1 / 56, \mathrm{p}>.50)$.

The time spent by $S$ while completing the schedule assigned on Day 14 is an alternate measure of the extent to which amount of prior exposure to Noyes pellets influences performance of an operant that yields pellet rewards. There was no significant difference between the 30 rats fed only Noyes pellets and the 30 rats that were fed almost exclusively on ground Purina $(F=.12$, $\mathrm{df}=1 / 56, \mathrm{p}>.50)$. Type of food used as the bulk of the rat's diet accounted for only $.06 \%$ of the total variation in these time scores!

Figure 1 shows the trend of mean body weights during all

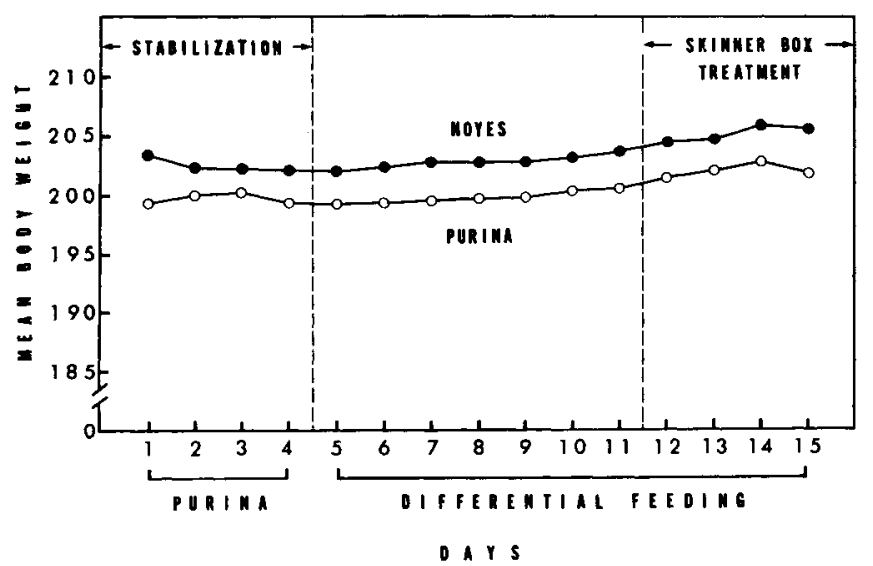

D I Y S
Fig. 1. Mean body weights during all phases of experimentation. 
phases of experimentation. Groups $\mathrm{N}-120 \mathrm{~A}$ and $\mathrm{N}-10 \mathrm{E}$ are combined into a larger groups labelled "Noyes." Groups P-120A and P-10E combined are labelled "Purina." The two curves are almost exactly parallel. Statistical tests indicate no reliable differences either between vertical points or with respect to trends.

\section{DISCUSSION}

The results suggest that an experimenter need not fear that Noyes pellets will lose their novelty or their full incentive value provided that experimentation does not involve the receipt of more than $220045 \mathrm{mg}$ pellets. Technically, the present results are specific to a situation wherein Ss have $22 \mathrm{~h}$ or more to recover from any "stimulus satiation" (Glanzer, 1953) associated with the pellets between any one session and the next. It is still possible that loss of novelty is a factor within a daily experimental session that involves receipt of many Noyes pellets.
The evidence very unequivocably indicates that Noyes pellets and Purina rat food can reasonably be regarded as nutritionally equivalent. This is a, happy result! An opposite result would have cast doubt on the validity of many hard-earned experimental findings.

\section{REFERENCES}

JENSEN, G. D. Partial reinforcement effects (PREs) and inverse PREs determined by position of a nonrewarded block of responses. Journal of Experimental Psychology, 1961, 62, 461-467.

GLANZER. M. Stimulus satiation: an explanation of spontaneous alternation and related phenomena. Psychological Review, 1953, 60, 257-268.

$$
\text { NOTE }
$$

1. This research was supported in part by a grant from the United States Public Health Service, National Institute of Child Health and Human Development, Grant HD-00945. 